Den empiristiske litteratursociologi behandles indgående i Kurt Aspelins artikel, som gennemgár en række eksempler pá denne type forskning. Min egen artikel behandler mere specielt den statsorienterede, socialdemokratiske litteratursociologi, som også Kjerstin Norén er inde på. Det er artiklens pointe ikke blot at kritisere denne type tankegang, men vise dens samfundsmassige baggrund og indre modsigelser. I Kjerstin Norẻns artikel gives på lignende máde en analyse af den ændrede samfundsmassige baggrund for forfatternes virksomhed og i sammenhang hermed den socialdemokratiske kulturpolitik. Peer E. Sørensen giver en epoke-bestemmelse af litteratur som til det borgerlige samfund knyttet fanomen, en problemstilling, som er af fundamental betydning for opbygningen af en historisk-sociologisk litteraturforskning. I artiklen angives, hvordan den samfundsmassige udvikling har frembragt de former, hvorunder litteratur typisk set produceres og konsumeres. Endelig giver Jette Lundby Levys artikel et konkret eksempel som baggrund for en diskussion af forholdet mellem ideologiske niveauer og litterar teknik.

Med disse artikler som baggrund skulle det vare muligt at bringe debatten om litteratursociologi nogle skridt videre.

Peter Madsen
Kurt Aspelin

\section{Om konsten att bortse från motsättningar}

Några synpunkter på "empirio-positivistisk" kultur- och litteratursociologi

Jag tror inte man kan finna ett mer belysande exempel på sammanhanget mellan den "empiriopositivistiska" kultursociologin och varufetischismens iđeologiska medvetanderam än en kort uppsats från 1966 av Harald Swedner, "Att marknadsföra kultur" (Ord och bild 75 s. 551-555). Den kan alltsł tjäna som utgăngspunkt for en kritisk granskning av en typ av litteratursociologi som sedan năgra ăr tillbaka fatt fotfäste $\mathfrak{i}$ sáväl undervisning som forskning inom den svenska litteraturvetenskapen. Utifrån den ser man klarare grundvalarna ocksł för den etablerade kulturpolitiken i Sverige (Litteraturutredningen är ett färskt dokument) och kan lättare fixera dess dilemma: dess făngenskap i rävsaxen mellan apologetisk retorik och krasst verklighetstvång.

Swedners artikel är sà mycket mer belysande, som den är formulerad utifràn värderingar som kunde kallas socialistiska. Inledningsvis sigger sig nämligen författaren själv inte acceptera "den privatprofitens ideologi som prägiar affärslivet i vârt samhälle" (551). Och han yppar vissa betänkligheter mot att applicera merkantilismens sprâkbruk pá kuiturfragor. Likafullt gör han det - kanske för att han tror att det gäller att möta "privatprofitens ideologi" på kulturfältet med dess egna vapen, för att besegra den. Vad han vägrar att se, är att han på så sätt i själva verket ger hela slaget förlorat. Ty med den strategin utlämnar han den "samhälleliga" kulturpolitiken just ât denna negativa ideologi - i samma ögonblick som han tror sig ha gjort kulturpolitiken stark nog att effektivt möta det privata affärslivets konkurrens. Politiskt sett kan Swedners resonemang sägas stâ som ett typexempel på hela den socialdemokratiska idéutvecklin. gen. Man vill övervinna privatkapitalismen genom en rad statliga ("samhälleliga") śtgärder. Men dessa ställs aldrig sả att de kommer att fungera antagonistiskt. De integreras i stället snabbt i samhällets allmänna kapitalistiska bas och tvingas lika snabbt att motiveras ideologiskt med det allmänna kapitalistiska sprakbruket (effektivitet, rationalitet, vinstmaximering etc.).

Poängen i Swedners artikel är tanken att distributionen av den "svårsălda" kulturen borđe bli en "samhällelig" angelägenhet. Pà sà sãtt skulle den undandras det privata kapitalets inflytande men samtidigt 
underläggas samma marknadskrafter som detta kapital - dvs. bli föremal för samma effektiva marknadsföring som konsumtionssamhällets materiella ting. Kulturens marknadsförare bör "vidta en lăng rad säljfrämjande átgärder, som i princip är av samma typ som de som producenten av frasflingor och bilar har på sitt marknadsföringsprogram" (553), såsom att målinrikta sig pâ en begränsad publik, anpassa sina varor till den och med alla medel övertyga den om köpets nödvändighet. (Reklamslogans som "Köp prestige med en kväll på operan" eller "Alla gillar Bach" anförs som exempel.)

Resonemanget har två huvudpostulat. För det första ses kulturfrágan primärt som ett distributionsproblem. Intresset kommer all tsá vid analysen varken att rikta sig mot produktionen och dess betingelser (och därmed de reella samhälleliga ägande- och maktrelationema) eller mot kulturproduktemas innehåll. För det andra poängteras att kultur inte är nảgot "sakralt", något som är förbehallet en "elit". Kultur skiljer sig inte kvalitativt frân andra produkter av mänsklig aktivitet, tex. sådana saluförda materiella ting som frasflingor eller personbilar. Därmed gör sig Swedner till talesman för en ovanligt tuff version av den "kulturdemokratiska" ideologi som företräddes vid 60-talets början av bla. socialdemokratiska och vänsterliberala ideologer.

Utifrałn den ideologi och den analysmodell han här föteträder, märker han inte att den "demokratiska" lösningen i realiteten betyder en anpassning till varumekanismerna under monopol- och statskapitalismens epok. Och märk väl: inte bara en "de facto"-anpassning, av det slag som vårt samhälle ständigt reproducerar och som för kultursektorns vidkommande har betytt att denna för länge sedan har dragits in under varumarknadens härskarmakt. Det är också fraga om en anpassning som innebär ett ideologiskt accepterande av denna härskarmakt, ett utnyttjande av dess grundläggande kategorier för analysen, en kapitulation inför dess utprovade språkbruk. Idag skulle det onekligen ligga närmare till hands att läsa uppsatsen som en medveten vänster-provokation, som en diabolisk parodi pá ett "falskt medvetande".

Det generellt intressanta med denna swednerska typ av "kulturell marknadsföring" är att den inte bara kan sägas modellera en viss typ av hårdför kultursociologisk fältundersökning (vilken Swedner själv inte sällan har dyrkat), utan ocksă överhuvud taget erbjuder en modell för den etablerade typen av konst- och litteratursociologi. Vađ gäller frågeställningar, problemomfang och funktion kan man nämligen tämligen noga parallellisera denna forskning med den kommersiella marknadsundersökningen för tex. en ny tvål eller en ny populärtidning. Likheterna når lángt utanför det metaforiska planet, in $\mathbf{i}$ de materiella och de ideologiska arbetsvillkoren. Helt följdriktigt avslutar Swedner sin artikel med att konstatera behovet av "en noggrann kartläggning" av de olika, gruppspecifika kulturattitydema i samhället, och därmed ocksta behovet av vetenskap. lig expertis:

Pa den punkten behöver kulturlivets marknadsförare samarbeta med skickliga fackmän inom sociologi och psykologì. Det är en förutsättning för att de skall lyckas i sin uppgift att marknadsföra kultur på ett effektivt sätt. (555)

Med detta sluter sig cirkeln. Kultursociologen bejakar - i "đemokratins" och "antielitismens" namn - kulturprodukternas plats pd vanumarknaden, och därmed ocksá den marknadsföringsmetod som är utbildad för att styra och stimulera köpamas konsumtionsbehov. Bejakandet gör att han ocksł väljer det kommersiella språkets begreppsapparat för sin vetenskapliga analys. Slutligen är tiden mogen forr honom att begära anslag till stora forskningsprojekt för att kartlägga "kulturmarknaden" och engagera forskarna i praktisk "kulturdistribution". Pa ingen punkt förmår han sá gå utanför de forrutsättningar som kommersialismens varumarknad skapar ăt honom.

En konst- och litteratursociologi $i$ tjänst hos den samhälleliga kulturpolitiken erbjuđer $i$ allmänhet föga av teoretiskt intressanta hållpunkter. Dess problematik tycks mig huvudsakligen ligga på ett praktiskt plan. Dels binder den forskama vid begränsade, mălbeställda undersökningsprojekt, vilka egentligen aldrig aktualiserar sådana frăgeställningar som pekar utöver den förelagda uppgiften. Följden blir en horisontkrympning till det yt-empiristiska och praktiskt-manipulativa. Dels tillhandahdller den samma forskare undersökningsmodeller, vilka binder dem ocksă vid de tillfällen de ställs inför undersökningar som aktualiserar en helt annan samhällelig och teoretisk medvetenhet. De frågeställningar som då kräver svar förblir osynliga, eftersom de inte kan formuleras med hjälp av tillgänglig metodik. Till slut rör man sig inom ett slutet universum, där frágoma är anpassade till svaren och svaren till fràgorna och där allt egentligt intressant och kontroversiellt faller utanför. Ju mer djupgáende krisen i kulturpolitiken kommer att te sig - parallellt med den allt hârdare dominansen frản lönsamhetskravets strukturrationaliseringar och den kommersiella kultur- 
monopoliseringen - desto gällare och ivrigare blir ropen på "expertutredningar" till tjänst at "samhället" och dess "beslutsfattare". Desto större blir också arbetsomrädet för en systemimmanent konstsociologi som nöjer sig med att at sina uppdragsgivare förpacka de väntade svaren hårddata-form och formulera sina reformförslag i det kommersialiserade samhällets reifierade språkbruk.

TCO:s utredning Kulturaktivt samhälle (1970) torde vara det hittills tydligaste exemplet pă en sådan tendens. Lika perspektivlöst deskriptiv som den inledande situationsinventeringen är, lika hårdfört effektiv är den avslutande delens skisserade reformförslag. Där skymtar en toppstyrd kulturbyråkratisk maktpyramid, vars uppbyggnad skulle betyda den korporatistiskt formerade kulturens slutliga triumf. Mitt emellan delarna framträder kultursociologen (Peder Hård af Segerstad) och ger vetenskaplig legitimering ăt helheten med hjälp av en del truistiska resonemang. Ideologin i utredningen ifrägasätter aldrig samhällets offentliga bild av sig själv. Tvärtom offrar den genomgàende ăt patosfyllt frasmakeri. Sverige är "ett land med demokratisk styrelse och fri ekonomi" (222); lösenordet för kulturskapandet måste vara "individen i centrum" (197); det gäller att utgå från "den enskilda människans situation" (ib.). I denna harmonimodell är de sociala motsättningarna bortopererade lika effektivt som de historiska perspektiven. Kulturpolitiken ska inte diskutera frågan om kulturutbudets innehåll och de produktionskrafter som behärskar och profiterar pá marknaden. Problemen gäller distribution och socialpsykologiska attityder.

I det följande ska jag granska de representativa bidragen till en "litteratursociologi" som accepterar basvärderingar och grundidéer hos den analyserade typen av kultursociologisk forskning. Jag börjar med en textantologi för universitetsbruk; därefter granskar jag kortfattat Robert Escarpits lilla populära introduktion till ämnet och slutar med tvă mer avancerade arbeten som söker anlägga en teoretiskt genomtänkt helhetssyn på forskningsobjektet. ${ }^{1}$ )

. Den skräddarsydda UKAS-volymen med relevans i detta sammanhang är den av Karl Erik Rosengren och Jan Thavenius redigerade Litteratursociologi (1970). Urvalet av svenska och utländska uppsatser är giort sả att det ska passa momentet "litteratur och samhälle" i de nya universitetskursplanerna och samtidigt exemplifiera den uppfattning av ämnet som utgivarna formulerar $\mathrm{i}$ forordet med följande ord:
Litteratursociologi / . . / skulle innebära att sociologisk teori och metod applicerades $p a ̊$ institutionen litteratur eller delar därav, i samma syfte som andra speciella sociologier arbetar: syftet att förstá ett samhälle, eller samhället, genom att sträva efter att formulera generellt giltiga, empiriskt prövbara utsagor om delar av samhället ifråga. (7)

Formuleringen kan tyckas oproblematisk. Men den rymmer svårigheter som förtjänar att lyftas i ljuset. Strax dessförinnan har författarna påpekat att denna litteratursociologi i sitt grannskap har tva andra fält som kan urskiljas under namn av sociologisk, resp. marxistisk litterarurforskning. Den förra vill i första hand "bidra till förstảelsen och upplevelsen av olika enskilda verk eller författaröden genom att sätta dem i relation till det omgivande samhället". Den senare skulle "i liknande syfte uttrycka sin samhällsbeskrivning $\mathrm{i}$ termer hämtade från Marx, Engels, Lenin och đeras efterföljare" (7). Det intressanta här är nu inte att diskutera dessa beskrivningars verklighetshalt och närmare innebörd. ${ }^{2}$ ) Det centrala är stället att framhäva författarnas teknik att med hjälp av en skenbart odisputabel avgränsning begränsa forskningsomrâdet till den speciella typ de själva vill främja, den empiriopositivistiska - och sá döpa den till litteratursociologi rảtt och slätt. Ovviga hänvisas allmänt till att bli något slags diffusa hjälpredor ât den vanliga litteraturvetenskapen. ${ }^{3}$ )

Det är all tsá viktigt att poängtera att det giorda valet för antologin Litteratursociologi alls inte följer ur någon allmänt accepterad vetenskapsfilosofisk grundsanning. Snarare bör det kallas ett ideologiskt val. Vilken ideologi det är frảga om, visar de valda texterna. Tydligast talar därom deras explicita ideologiska ställningstaganden. De förekommer ymnigt, inte minst i de teoretiskt foga intressanta bidrag som sysslar med kulturpoliti. ska klarlägganden och alltså snarast exemplifierar đen målstyrda typen av kultursociologiska undersökningar. Här är det politiska innehăllet genom. găende "reformistiskt" (i liberal eller moderat socialdemokratisk mening). Högst naivt är det formulerat $i$ en norsk uppsats on teatern $i$ dagens samhälle (av Amljot Strömme Svendsen). Författaren använder utan betänkande ett begrepp som "välfärdsstaten". Han kräver "kulturpluralism" och förespråkar ett forskningsprogram, initierat av regeringen och utfört av "sociologer, psykologer, nationalekonomer, marknadsföringsfolk, statistisker" etc. (232). Inte på någon punkt tycks han ana att săväl honnörsord som projektskiss är strömlinjeformat till de samhälleliga makthavarnas apologetiska behov.

Ett följande bidrag av Harald Swedner (presenterande resultat ur en enkätundersökning om "teatervanor") kan stă som en illustration till 
väntade resultat av sảdana undersökningar. Det är en samling data utan vare sig teoretisk eller saklig sprängkraft, av intresse blott för en närsynt kulturell ad-hoc-politik frán "samhällets" sida. Inte ens Raymond Williams - som i andra sammanhang kan framträda med vissa kritiska och kontroversiella analyser - far här komma till tals med annat än en tankemässigt ovanligt luddig, snarast kulturliberal lösning av kontrollsystemet för "masskulturen"; dess vetenskapliga innehäll är frapperande rudimentärt. Men tydligast yppar sig värderingarnas art i Lennart Thorsells studie "Den svenska parnassens 'demokratisering' och de folkliga bildningsvägarna". Med sympati citerar författaren ur socialdemokraternas kulturprogram frản 1952. Där suggererades föreställningen att demokratiseringen av de ekonomiska, sociala och politiska förhalllandena i stort sett var avslutad; vad som ăterstod var en frigörelseskamp som gällde de (social-) psykologiska aspekterna. En sådan samhällsanalys av typiskt reformistiskt 50-talssnitt vägleder nu Thorsell fram mot insıkten att "klassutjämningen" är ett nära nog fullbordat faktum (se formulering s. 75) och att "alla klasskampsaspekter" i frága om attitydema till kulturella värden har blivit föråldrade (76). Här är "litteratursociologen" öppet verksam för att idyllisera verkligheten: hans funktion är apologetisk.

Av annorlunda, och i grunden kanske av mer belysande slag, än dessa prov pà ytvärderingar är de exempel pa ideologisk styrning som talar ur de valda vetenskapliga modellstudierna. Tva bidrag må vara tillräckliga att uppmärksamma. Det första är William Charvats "Litteratur och ekonomi". Det gör ansprảk på att blottlägga förbindelsen bokmarknad-litterär gestaltning med exempel fran nordamerikanskt 1800 -tal. Men den stannar vid den ytligaste "ekonomistiska" aspekten och förmår inte se dess sammanhang med den samhälleliga totaliteten; resultatet blir en uppsats som paradoxalt nog påminner om vissa "vulgärmarxistiska" fadäser. Charvat kan gå så långt i sina formuleringars aningslöshet att han hävdar, att Poes noveller och Melvilles Moby Dick är skrivna av "en konstnär i harmoni med samhället" (92). Vad han menar, är att de är skrivna av författare, som söker etablera publikkontakt på förlagsmarknadens villkor. Han vill inte se att den "läsarsmak", pà vars sida han ställer sig med hela uppbådet av kulturdemokratismens ideologiska patos, är en skapelse just av den kulturella varumarknad vars ödesdigra inverkan på det estetiska skapandet är ett så framträdande fenomen redan under 1800-talet.

Det andra exemplet jag väljer är Walter Hirschs innehăllsanalys "Bilden av vetenskapsmannen i science fictionlitteraturen". Hirsch anslår omedelbart tonen: hans studie vill "fylla ut en del av klyftan mellan â ena sidan humanisternas stimulerande men impressionistiska undersökningar och å andra sidan de krav på tillförlitlig kunskap, som innehállsanalysen strävar att tillfredsställa" (110). Den utlovade "tillförlitliga kunskapen" visar sig vara en samling hărddata-fakta, som visserligen är ordnade med stor metodisk rigorism men som aldrig når kontakt med sådana större samhälleliga sammanhang som hade kunnat ge dem en intressant belysning. SF-författama vill han se som "talesmän för den vetenskapliga andan" (118) - onekligen en något mysteriös och ogripbar storhet! - och behöver därför aldrig sätta deras produkter i samband med (tex.) samhällets behov av verklighetsbeslojande myter och överhuvud dess ideologiska manipulering. Ånnu mindre görs năgra försök att antyda đe ekonomiska intressena bakom denna populärlitteratur-industri. Ett kort ögonblick dröjer Hirsch vid det bekanta fenomenet att efterkrigstidens amerikanska SF-litteratur uttrycker kraftiga tvivel på naturvetenskapens förmága att lösa världens överhängande problem; i stället konstaterar undersökningsmaterialet en ökning av "ingripande av 'främlingar' (t.ex. invănare frán andra planeter)" (117 f.). Men eftersom en belysning av denna iakttagelse skulle ha krävt analyser pd ett vidare ideologiskt och ideologikritiskt plan, liksom kanske inbrytningar på en mer gnundläggande social och politisk niva, så faller frågeställningen snabbt utan att năgra svar prövas.

Textantologin som helhet belyser realinnehăllet $i$ den motsättning mellan "tillförlitlig kunskap" och "humanisternas stimulerande men impressionistiska undersökningar" som Hirsch ville etablera i sin uppsats och som Rosengren själv ocksa har formulerat utifrân samma falska alternativ. Man säger sig alltså välja "tillförlitlig kunskap". I själva verket väljer man det systemimmanenta. Samtidigt väljer man bort det meningsfullt systemsprängande och horisontvidgande. ${ }^{4}$ )

För att fá perspektiv på den typ av längt mer sofistikerad, och primärt teoretiskt arbetande, litteratursociologi som mitt slutavsnitt ska granska, tjänar Robert Escarpits lilla introduktion i ämnet som lämplig startpunkt, Litteratursociologi (sv. övers. 1970). Boken är inte riktigt representativ för den renodlade empiriopositivistiska typen. Dess författare har exempelvis ambition att göra viss rättvisa ăt de bredare historisk-sociala perspektiven på de frágeställningar han tar upp (kanske är förklaringen att han ursprungligen kommer frản den franska littérature comparée). Han kan tom. någon gång yppa influenser från sáväl sartresk existentialism som marxism. ${ }^{5}$ ) Bristen pá teoretisk fördjupning är emellertid samtiđigt ytterst pataglig hos honom. I huvudsak kommer han därför att halla till godo med den "ytans fenomenologi" som är ett av positivismens kännemärken och 
som hans oreflekterade metodpluralism egentligen bara ytterligare underbygger.

Escarpit uppträder som om begreppen samhälle och litteratur var omedelbart givna - och inte problem att inringa och lösa. En sådan systemimmanens far viktiga följder. Det gör att han utan närmare eftertanke öppnar utsikten mot litteratursociologins förvandling till en integrerad del av den samhäleliga litteraturpolitiken. Vad är fö. mer logiskt, om man som han ser det kapitalistiska samhället som platsen för "Massomas" höjande (15)? Då kan man ocksa, som han, efter viss tvekan acceptera kommersialismens syn pá litteraturen och tillfoga, att den sociologiska betraktelsen inte bara är nödvändig utan "också lönande". (21. - Sid. 20-22 ger flera exempel på en sảdan lăngt ifrăn charmerande naivitet.) Viktigast $i$ sammanhanget är emellertid följderna av hans a.teoretiska utgangspunkt. Litteratursociologins falt kommer $i$ stort sett att inskränka sig till en författarnas, bokens och bokspridningens sociologi pá det omedelbart iakttagbaras plan. Att återföra ytfakta pá djupare sammanhang blir här lika lite aktuellt som att kritiskt ifrägasätta. Forskaren nöjer sig med att systematisera vad han "ser", utan att frăga sig om det kunde finnas alternativa möjligheter till hans seende. "Det är all tsa", heter det med en ovanligt öppen formulering av den metodiska empirismen i boken, "genom studiet av objektiva, systematiskt utnyttjade fakta och utan förutfattade meningar som man bör närma sig litteraturen" (34).

Resultatet blir en samling handfasta fakta, översiktligt-pedagogiskt ordnade och ibland försedda med intresseväckande utvikningar; men utan en teori för "litteraturen" och "samhället" och för relationen dem emellan. I stället lämnas fältet fritt för författaren att pendla mellan vag idealism, närsynt empirism och apologetik. Den förra ytterligheten kan exemplifieras med Escarpits närmast kantianska definition på litteraturen som "varje icke-funktionell lektyr, dvs. den som tillfredsställer ett icke-utilistiskt kulturellt behov" (29). Den senare, apologetiken, kan appliceras på de korrelerade termer Escarpit använder för att beskriva de tvă härskande litterära distributionsfälten, "det bildade", resp. "det populära kretsloppet". Deras inneháll blir systembekräftande, eftersom begreppen inte ställs i sammanhang med en teori som kunde analysera de samhälleliga maktförhallandena. Det är ju dessa strukturer som betingar utformningen av det övergripande litterära systemet och bestämmer sådant som bokförlagens specifika funktion i ett monopolkapitalistiskt system, den ideologiska manipuleringens plats, och framför allt de socio-ekono- miskt satta skrankor som definierar populärlitteraturens plats, villkor och funktion $i$ ett sådant samhälle.

För Escarpit faller det litterära verket bort som undersökningsobjekt. Kvar står fakta kring diktverket, närmare bestämt data samlade kring de tre momenten produktion-distribution-konsumtion. Begränsningen bygger inte på nảgot explicit formulerat resonemang. Teorin fór en sådan litteratursociologi tillhandaháller i stället Hans Norbert Fügen i sín dissertation Die Hauptrichtungen der Literatursoziologie (1. Aufl. 1964). Här intresserar bara de partier där Fügen redogör för den riktning han själv forreträder. Det blir ett ovanligt klart formulerat stälningstagande till förmăn fồ en "speciell litteratursociologi" av empiriopositivistiskt slag. (Parentetiskt bör dock nämnas att han utformar sitt program i tydlig opposition framför allt till den marxistiska riktningen, som här fö. blir föremål fơr en tämligen otillfredsställande belysning.) I inledningen till sin senare textantologi Wege der Literatursoziologie (1968) - ett skickligt giort urval uppsatser, belysande fältet sảväl historiskt som systematiskt och med tämligen vida perspektiv - sammanfattar han programmet i kanske än mer renodlad form och formulerar nya polemiska adresser till săväl marxismen som Adorno-skolans "kritiska teori" (varunder det är lätt att avlyssna hans irriterade reaktioner på den aktuella vetenskapliga kontroversen som fatt namnet "positivismstriden i tysk sociologi").

Litteratursociologin fär för Fügen samma status som underavdelningar av typ familje-, rätts- eller fritidssociologi. Den blir dessutom en "bredvid-vetenskap" genom att diktverket, det litterära objektet, sätts inom parentes och någon förbindelse mellan samhällelig verklighet och estetiskt uttryck aldrig etableras. I stället ska den studera litteraturen som "socialt fenomen" och "institution". Häri bildas huvudelementen av författare (och författargrupper), publik och litteraturförmedlare; mâlet är att på grundval av strängt empiriska fakta och med en "värderingsfri" metodik bygga upp en abstrakt modell av det litterära systemet som autonom verklighet. Tanken är som synes starkt präglad av den etablerade sociologins "modellplatonism" (jfr. tex. Talcott Parsons), där samhällsbegreppet toms pá all konkret innehall och sammanhanget med den materiella basen och de därav betingade medvetandeformerna är avklippt. I en sàdan modell är verklighetens motsättningar och konflikter borta, möjligheterna principiellt uteslutna att några iakttagelser skulle öppna ett fönster ut mot det samhälleligt annorlunda. I inledningen till Wege der Literattursoziologie - där mălsăttningen för en vetenskaplig litteratursocio. 
logi begränsas till studiet av "literarisches Verhalten", litterärt beteende anger Fügen som orsak till att det litterära verket inte blir foremal for analys, att ett sådant studium inte kan uppfylla de vetenskapligt oundgängliga kraven på verifikation. Positivisten löser allts̊̊ som vanligt den hermeneutiska problematiken genom att làta den försvinna. ${ }^{6}$ )

Karl Erik Rosengrens avhandling frân 1968, Sociological aspects of the literary system, är mig veterligt det internationellt mest konsekventa försöket att konstituera litteratursociologin som ett vetenskapligt delområde, enligt en grundsyn baserad pá den etablerade universitetssociologiens abstrakta modellteori. Som sådant måsta arbetet sägas vare ambitiöst och djärvt, och dessutom genomfört med avsevärd precision. Fügen skisserar allmänt hur detta fält ska ta sig ut. Rosengren förverkligar programmet $i$ en bestämd undersökning, vars mălsättning sägs vara "mainly methodological" (18).

Det gäller för Rosengren att finna strukturer i "det litterära systemet" med hjälp av litteraturkritiken under två kortare tidsperioder (1880-talet och 1950- och 60-talet). Som en preliminär kartläggning av ett stort material torde hans kvantitativa arbe tssätt äga atskilliga fördelar. Och hans sätt att använda "mentions" (ett "omnämnande" föreligger, när en recensent nämner en annan författare än den hans artikel är ägnad) är onekligen både uppslagsrikt och användbart. (I antologin Litteratursociologi 141-162 presenteras centrala partier ur avhandlingen i översättring; där ăterfinns huvudparten av de partier jag anknyter till i fortsättningen.)

Så snart man emellertid är intresserad att nả nảgot mer än en kvantitativ systematisering, kommer avhandlingens "scientistiska" rigorism att fungera som en tvángströja. Då aktualiseras nämligen bristen på kvalitativa materialanalyser och överhuvud taget vidare referensramar. I sin tidigare uppsats från 1966 hade Rosengren sett hur hans socjologiska metodik sitter i klän mellan kravet på "verifikation" och viljan att formulera något "intressant". Där ștväl som här väljer han det verifierbart truistiska. Möjligheten att ställa frảgor på ett djupare samhälleligt plan - bland dem också słddana fragor som en rent traditionell litteraturhistoria sannolikt $\mathbf{i}$ varje fall hade skymtat - är tillbommad genom metodvalet. Därtill kommer att det litterära systemet blir en verklighetstom abstraktion: "modellplatonismen" utesluter varje antydan om systemets motsägelsefulla dynamik, dess sammanhang med samhällets maktstrukturer och ideologiska mönster. Och "mentionerna" reduceras till mekaniskt producerade rådata; utanför blickfältet ligger tom. sádana frảgor som om de är positivt eller negativt laddade, vilken grad av relevans de har i sammanhanget, vilken representativitet de kan göra ansprâk på i pressvärlden, etc.
Själv vill Rosengren hävda att hans eget arbetssätt är på en gång snabbare och lättare än det vanliga. Därtill är metoden objektì i motsats till samma "traditionella"7) och "impressionistiska" forskning. Men den "objektivitet" han talar om - som alltsâ skulle göra resultaten "independent of the investigator" (33) - reducerar hela problematiken till en enkel frałga om mätning. Vad som mäts lämnas utanför, liksom frågan om den nödvändiga tolkningen av det material som ska mätas. Vad det är frăga om, är positivismens vetenskapsfilosofiska otillräcklighet. Åven om en rad andra forskare fortsatte att med samma arbetsflit och utifrán samma metodologi "combine data into a quantitative and 'neutral" description in general terms" (21), och därur dra allt fler "subteorier", så skulle likväl det adderade resultatet av all denna möda aldrig kunna ge mer utbyte än de enskilda torftigheterna var för sig. Och den framtidsvision Rosengren ställer fram - nämligen möjligheten att litteratursociologiskt "formulate general propositions concerning certain aspects of human social behaviour" (ib.) - skulle erbjuda måltavla för precis samma grundläggande kritik som hans eget arbete inbjuder till.

En genomgàng som denna av ett representativt urval texter av kultur- och litteratursociologiskt slag ter sig onekligen tämligen monoton. Enahanda kritiska synpunkter kommer att formuleras inför text efter text. Orsaken ligger primärt $i$ den empiriopositivistiska modellen själv: så effektivt stänger den inne forskaren med en mall $i$ handen som ska lösa de mest skiftande uppgifter enligt samma schema.

Han kan välja det närsynta datasamlandet och nöja sig att redovisa sina fynd enligt "det sunda förnuftets" förrädiska normalsanningar, som verklighet en brut. Eller han kan bygga ett modellsystem av abstrakta diagram, tabeller och figurer. I bägge fallen missar han vetenskapens främsta malsättning, som är att kartlägga verklighetens djupare objektiva sammanharig och sedan ställa dessa resultat till förfogande för de samhälleliga krafter som är intresserade av en sådan verklighetsavslöjande forskning. I stället kommer hans vetenskapliga funktion att bli affirmativ, stabiliserande. De frảgor är nämligen a priori utelämnade som skär rakt in $\mathbf{i}$ de samhälleliga maktförhállandena och ifrågasätter de härskandes legitimitet.

Avståndet kan tyckas mycket lángt mellan exempelvis TCO:s kulturutredning a ena sidan, à den andra en renodlat teoretisk-metodologisk undersökning som Rosengrens avhandling. Det förefaller mig emellertid väsentligt att peka på samhörigheten mellan dem, de osynliga band som 
knyter dem till varandra genom ett samförstănd i allmänt synsätt och grundinställning. Mitt emellan ligger så det vida fält där kultur- ơch litteratursociologer än uppträder som vetenskapsmän och än som kulturpolitiker - och där vetenskapen, utan ett stort mătt av självreflexion och politisk medvetenhet, ständigt riskerar att ställa sig i tjänst hos makten. För en marxistiskt inspirerad vetenskapssyn máste det höra till de mer primära uppgifterna att kritisera såväl innehall som funktion i denna art av kultur- och litteratursociologi. Anteckningarna i denna uppsats făr ses som ett preliminärt försök $\mathrm{i}$ denna riktning.

\section{Noter:}

1) Vill man fă en allmän, snabbläst översikt av det aktuella fältet, erbjuder sig Lilian Nowaks Bokläsaren (1971), som snarast kunde kallas en resonnerande bibliograf. Här marscherar de upp, alla de som i sin forskning orienterar sig mot kulturpolitik, litteraturpedagogik och "kulturell marknadsföring". Författaritnans urval är strängt begränsat till den beteendevetenskapligt präglade lifteratursociologin och helt lojalt mot dess grundlïggande värderingar. (A tt Lukács och Sartre blir nämnda $i$ inledningen, $13 \mathrm{f}$., bör vara ett rent misstag och tar ing foljder senare.) Helt foljdriktigt visar en rad formuleringar $i$ inledningen (13-19), hur beroende boken är av det begynnande 60-talets "kulturdemokratiska" debatt; reflexer av den senare starka kritiken mot dess i grunden marknadsliberala premisser ska man inte leta efter i hennes framställning. Să kan hon också j samma andetag positivt anknyta till UKAS-modellen och härunder taln om "năgot av ett genombrott för litteratursociologin under de senaste två åren" (19). Här far onekligen UKAS den typ av forskningsöversikt för momenten "litteratur och samhälle" och "litteratur och mottagare" som den har behov ay!

2) Jag menar att beskrivningarna är högst otillfredsställande. För att peka pă en enda detalj: skolle inte en marxistisk litteraturforskning tex. intressera sig för at fastställa historiska utvecklingslinjer eller objektiva generella samband mella litteraturen och den sociala formationen vid en viss tidsperiod?

3) Som bakgrund för avgränsningen bör man erïnra om vad Kard Erik Rosengren hade att säga om problematiken i en tidigare uppsats, "Litteratursociologi - sociologisk litteraturforskning" (tryckt i samlingsvolymen Litteraturvetenskap. Nya mdl och litteraturforskning" (tryckt i samlingsvolymen Litteraturvetenskap. Nya mal och forvissad om att hans litteraturvetenskapliga kollegor skulle táta sig imponeras ocksà av handbokskunskaper i det ämnet, redogjorde han där fór en del elementa och tog sig samtidigt för att väga tidigare litteratursociologiska prestationer, blott öt att - själuklart - finm dem inte halla máttet. Victor Svanbergs forskningar kan, hette det, pd sin höjd betecknas som "imponerande lardomsprestationer" men har inget med vetenskap i strängare mening att göra; Lucien Goldmann är "tămligen metafysisk". Så mycket hărdare formulerade han programmet för sin egen positivism: naturvetenskapens stränga formalisering är modelien, kvantifiering nära nog oundgänglig. I annat fall kallas forskningen med en älsklig term "impressionistisk" - alternativet till den egna "objektiva" är alltsă blott en metod- och principlös, essäistisk litteraturavsmakning!
4) lllustrativt tycks det mig varn att jämfora Charvats, resp. Hirschs uppsatser med vad som gjorts utifran andra litteratursociologiska u tgàngspunkter kring de av dem berorda renomenen. Det pavra resultatet av den forres satt att narma sig den kulturella varumal Det pla uppsatsen studers parallellh med vad lex. Walter Benjamin, Georg Lukács eller Amold Hauser hafl att saga om konsten och "Lar Betischimen springer torftigheten I Hirschs framstalling omedelbart i gonen vid en jamforelse Fleming studie (Őers i Form och straktur 1971).

5) Att Escarpits forskargrupp i Bordeaux överhuvud taget präglas av viss teoretiskmetodisk öppenhet, demonstreras tydligast av dess sumling uppsatser Le littéraire et le social. Eléments pour une sociologie de la littérature, Paris 1970. - Den uppsats av Escarpit som är medtagen i Rosengren \& Thavenius' antologi liten oppning at altemativa modeller. I stort inrangerar den sig emellertid i helheten.

6) I Fügens vetenskapsmodell blir diktverken relevanta, bara i den mìn de kan ge material som belyser författamas norm- och värdesystem, resp. de norm- och värdesystom som bär upp den sociala grupp de tillhör eller den publik som läser dem. Hur en sảdan undersbikning ska lanna göras utifrán for Fïigen giltiga vetenskapling kna förblir emellertid i dunkel: ocksả dessa värdesystem mäste väl hermeneutiskt utlïsas ur verkens "innehalll" och allts rimligen te sig lika svărả tkomliga som det övriga som ingà däri.

7) "Traditionell" här alltsł blott i jämforelse med litteraturhistorisk forskning. Ur sociologisk synpunkt âr ju metodiken ocksa för svenska förhallanden snarast "traditionell"! Man ser hur Rosengren växlar roll efter hur det passar: här uppträder han płötsligt i sina gamla skepnad som litteraturforskare, fastän dissertationen närmast hör hemma i ett akademiskt sociologiskt sammanhang. 